\title{
The enhancement debate
}

\author{
Bert Gordijn · Henk ten Have
}

Published online: 11 December 2013

(C) Springer Science+Business Media Dordrecht 2013

Although a plethora of theoretically imaginable enhancements have already been subjected to ethical analysis, the discussion about enhancement is still on the move. When the discussion on mood enhancement slowed downamongst others due to disappointing results of Prozac-the debate on moral enhancement gained momentum: the latest type of enhancement to stir up ethicists' spirits. Some authors see moral enhancement as a sine qua non for the long-term survival of humanity (Persson and Savulescu, 2012 , p. 121, 133). Others regard it as a perilous technological fix that might lead to far-reaching forms of selfalienation (Briggle and Wenlong, forthcoming).

As with many other normative debates, the moral disagreement about enhancement seems to be partly based on more fundamental conflicting descriptive points of view. Some of the pros and cons of enhancement, for example, can be traced back to different anthropological premises. Enhancement enthusiasts tend to see human beings primarily as flawed biological products of a long evolutionary process of natural selection, whereas thinkers who regard persons as principally spiritual beings or as created by God intuitively lean towards being more critical of enhancement. Another chunk of the disagreement is based on different expectations of technology. Techno-optimists are aware that technology creates difficulties. However, they have a strong believe that adding more technology to the equation will solve these very hitches. Others have a more sober, skeptic or even suspicious look towards

\footnotetext{
B. Gordijn ( $\square)$

Dublin, Ireland

e-mail: bert.gordijn@dcu.ie

H. ten Have

Pittsburgh, PA, USA
}

technological approaches of important problems. Yet another part of the disagreement seems to be linked with divergent expected psychological and societal effects of different types of enhancements. Whereas it has been argued that widespread use of enhancement can lead to increased inequalities, it has also been pointed out that it will boost innovation and promote good consequences overall.

In "Moderate eugenics and human enhancement" Selgelid (this issue) argues that it is necessary to deepen the enhancement debate through further exploration of some of the descriptive disagreements underlying the enhancement debate. Selgelid argues that it is pivotal to balance liberty, equality, and utility when discussing the pros and cons of individual enhancement technologies. The introduction of certain enhancements might, for example, create such dreadful equality and utility costs that these effects might justify a ban and thus liberty infringements. Other enhancements might have more beneficial effects, making it difficult to justify curbing our freedom to use them.

However, it is not easy to predict the social impact of particular enhancements in terms of equality and utility. In order to address these questions more fruitfully, further empirical research is needed. Philosophers have an important role to play in framing the empirical questions relevant to the ethical debate. Psychologists, sociologists, anthropologists, political scientists, and economists amongst others should then, in turn, further investigate these questions from their particular disciplinary perspectives.

Selgelid makes a further helpful suggestion about the discussion on the therapy/enhancement distinction. Instead of unsuccessfully trying to identify a precise demarcation between therapy and enhancement, or dismissing the distinction altogether, he argues that it makes more sense to imagine both sitting at the opposite ends of a continuous 
scale. Interventions clearly at the enhancement side of the scale are usually increasing social inequity, whereas interventions plainly at the therapy side tend to be furthering equality.

In the next article, Heilinger and Crone (this issue) focus on the use of arguments related to human freedom in the enhancement debate. As enhancements can have both positive and negative impacts on freedom, corresponding arguments are employed in both camps of the debate. The authors distinguish six different freedom arguments that are used by proponents of enhancements, as well as an equal number of arguments advanced by enhancement critics. Unsurprisingly, different senses of "freedom" figure in these arguments. Having identified these different senses of freedom, Heilinger and Crone rank the arguments according to their salience in liberal societies.

Next, Enck and Gavin (this issue) looks at the use of cognitive enhancements by medical professionals. He first reviews emerging empirical data demonstrating that a significant number of young medical professionals have used cognitive enhancers. In addition, he tackles the ethical question of whether there are situations, in which medical professionals would have a duty to use enhancers in order to improve patient care.

Finally, Zwart (this issue) analyses the fiction thriller Limitless, tackling both the movie released in 2011 and the novel published 10 years earlier, in which the main protagonist, a novelist with a writer's block, starts using cognitive enhancers. At first, there seem to be only desirable effects, but later on horrid side effects pop up as well. Zwart interprets this piece of fiction as a pharmaceutical research trial, building on the views of Emile Zola. In addition, he looks at how the enhancers affect the main character's way of being-in-the-world, referring to Ludwig Binswanger's phenomenology of spatiality. Building on these two accounts, Zwart then advances an argument for the usefulness of fiction in anticipatory ethical debates.

\section{References}

Briggle, A. and Wenlong, L., Ingmar Persson and Julian Savulescu, Unfit for the Future: The Need for Moral Enhancement Oxford: Oxford University Press, 2012. Forthcoming in Environmental Values (http://www.erica.demon.co.uk/EV/EVrev.html).

Enck, G.G. Pharmaceutical enhancement and medical professionals. Medicine, Health Care and Philosophy 17(1) (this issue).

Heilinger, J-C. and Crone, K. Human freedom and enhancement. Medicine, Health Care and Philosophy 17(1) (this issue).

Persson, I., and J. Savulescu. 2012. Unfit for the future: The need for moral enhancement. Oxford: Oxford University Press.

Selgelid, M.J., Moderate eugenics and human enhancement. Medicine, Health Care and Philosophy 17(1) (this issue).

Zwart H., Limitless as a neuro-pharmaceutical experiment and as a Daseinsanalyse: on the use of fiction in preparatory debates on cognitive enhancement. Medicine, Health Care and Philosophy 17(1) (this issue). 